\title{
A Probe into the Fusion of Ceramic Art and Design and Traditional Graphic Elements in Art Teaching Course in Colleges and Universities
}

\author{
Cai Sha \\ School of Arts of Xi'an University, 710065
}

\begin{abstract}
Keywords: Art teaching course in colleges and universities; Ceramic art and design; Traditional graphic elements; Probe into fusion
\end{abstract}

\begin{abstract}
China has many characteristic synonyms globally, such as panda, Chinese food and Chinese Kung $\mathrm{Fu}$, which is elements with Chinese characteristics, having a great influence all over the world, and ceramic is one of the things that have to be mentioned when talking about China. The English name of ceramic is "china", which is the same with the country name "China", thus its representativeness is self-evident. Ceramic in China has a long history; according to researches conducted by scholars, ceramic development has a history of eight thousand years, and ceramic is of Chinese historical characteristics and unique Chinese style. At the earliest stage of ceramics, people added patterns of a variety of flowers, birds and beasts, and stories onto ceramics to increase sense of beauty, and then with development, the ceramics were added with geometric figures and had different shapes. It can be said that the history of ceramic development is an inseparable section of thousands of years of Chinese history. In the art teaching course in colleges and universities, the fusion of ceramic art and design and traditional graphic elements inevitably becomes a meaningful attempt. The present paper mainly studies the background and current situation of ceramic art and design, and expounds the fusion of ceramic art and design and traditional graphic elements, hoping to bring some inspirations to relevant professionals.

Ceramic is an extremely important existence in Chinese history; its development has a long history, which can be traced back to the Neolithic period, and it can be said that the history of ceramic development contains the history of Chinese human-culture development. During development, the ceramic experiences a transformation from stoneware to art with a large time span. Ceramic experiences different periods, and its style and innovative features are of unique characteristics of the times, resulting in a wide range of ancient porcelain works now we have seen, and meanwhile adding more elements and patterns of manifestation for the art of ceramics, creating more possibilities and artistry. Also, its style is also full of tension in performance. In the long history of China, there are a variety of graphic elements, and the most common traditional graphic elements are decorative figures and ornamentations indicating auspiciousness. Different graphic elements and ornamentations have different meanings, thus their uses are also different. In the art teaching courses in Chinese colleges and universities, fusion of the traditional graphic elements and the ceramic art, which is of Chinese characteristics, must be a very meaningful attempt, and such an attempt will have a far-reaching influence. The background of ceramic art and design and its current situation were analyzed below.
\end{abstract}

\section{The Basic Content of Ceramic Art and Design}

The Background of Ceramic Art and Design. With the progression of times and development of society, the information technology is rapidly developed, and the exchange between countries becomes more convenient. The distance between countries is gradually being shortened; in this context, Chinese ceramic art develops more quickly. The informatization of science and technology makes the global art exchange become more convenient, resulting in increase in cultural exchanges between China and the western countries, and there are gradually many examples for fusion of Chinese and western art. At present, some western cultures are also integrated into Chinese ceramic art. Ceramic art is originated from China with thousands of years of history, and is endowed with great Chinese characteristics. Nowadays, ceramic art has received global attention, and a large number of art workers of the western art world are emerging to study the art of ceramics, indicating 
that ceramic art has become more and more international. At present, although Chinese ceramic art has adopted the advantages of western technology, most people still adhere to the Chinese porcelain technology; thus there is still difference in current ceramic art between China and western countries. There must be problems during the development of anything, and then solutions are suggested, and finally the problems are solved. Therefore, although the occurrence of problem means difficulties, it indicates the beginning of development; for the current Chinese ceramic art and design, the infusion with traditional graphic elements is a very meaningful innovation.

The Current Situation of Ceramic Art Development. At present, the development of contemporary ceramic art includes three stages, namely, the ceramic art based on patterns of manifestation of conceptual art, the audience's appreciation of contemporary ceramic art, and the contemporary Chinese ceramic art combined with western ceramic art concept. The first stage is mainly from the twentieth century; China gradually began to accept the western ceramic art, and Chinese ceramic art began to change. The introduce of western ceramic art brings a cultural shock to the traditional ceramic art of China; ceramic art at that time as a traditional ancient art began to usher in a new developmental background and began to fuse with modern culture, and a number of new art forms appeared. The second stage mainly refers to the gradual fusion of sense of art after breakthrough of the forms of ceramic art. Ceramic art in China has always been an ancient art with a history of thousands of years, during which a variety of forms and decorative patterns of ceramics appeared, forming a unique style of Chinese ceramic art. However, since the technology of Chinese ceramics has been very mature and has a long history, it will be difficult to break through its original style for innovation. The third stage mainly refers to the infusion with western ceramic art. In western ceramic art, the most valued section is not only the artistry of ceramics, the participation is also very important. Compared to the results, the western ceramic art pays more attention to the process of making porcelain, so the process of making porcelain in the western countries is not only an art, but also a life experience. If the art has its own unique performance language, the performance language of western ceramic art is the making process of ceramic. It is believed that if the western ceramic culture and Chinese ceramic art and design are fused, Chinese ceramic art will make more progresses under the influence of western ceramic culture.

\section{The Fusion of Ceramic Art and Design and Traditional Graphic Elements}

Infusion of Traditional Graphic Elements into Ceramic Art and Design. Ceramic in China has a history of more than eight thousand years; from its emergence to the development, and then to its inheritance and transformation, ceramic has gone through a long period of time and the alternation of the dynasties, forming a unique style of Chinese ceramic art. The traditional figures are also the cultural and artistic elements of thousands of years of Chinese history. Fusion of traditional figures and ceramic art will inevitably lead to unexpected artistic achievements and create more miraculous possibility. The fusion of traditional graphic elements and ceramic art dates back to the Qin and Han Dynasties. At that time the earliest embodiment of this fusion is the upper string lines on ceramic products; the width between string lines and the shapes of the curves on ceramic products at the time are different, and the string lines can be matched with other patterns on the ceramic products, thus the styles of ceramics are various, and the ceramic appearances are diverse. In the Eastern Han Dynasty, Buddhism was popular in China, and figures of Buddha were naturally drawn onto the ceramic products, greatly improving the beauty and richness of ceramic products. Experienced the alternation of several dynasties, the fusion of ceramic art and traditional graphic elements had a new peak in the Sui and Tang Dynasties. The embossment made by clay applique technology created novel style of ceramic products, greatly enhancing the beauty of ceramics. Tang Sancai ceramic is familiar even in the modern society; its consummate craftsmanship, unique beauty and novel style are among the best. Tang Sancai ceramic is the best embossment for fusion of the cultures of the Western Regions, India and other countries and China. Later in the Song Dynasty, many paintings began to be drawn onto the ceramic products, such as lifelike dragon and phoenix, mandarin ducks, beasts and birds and other animal patterns, magnificent mountains and rivers or landscape painting and patterns of flowers with a variety of colors. The blue and white 
porcelain firstly emerged in the Yuan Dynasty with mainly flowers-based patterns and exquisite craftsmanship. The heyday of blue and white porcelain is in the Ming Dynasty; the patterns of ceramic products are in an elegant style. The porcelain in Ming Dynasty not only includes blue and white porcelain, colorful Wucai is also very distinctive, and different from the elegant style of blue and white porcelain, it is colorful, and mostly painted with patterns meaning auspiciousness.

Innovation of Traditional Graphic Elements in Ceramic Art and Design. In order to integrate the traditional graphic elements into the modern ceramic art and design, we need to fully master the characteristics of traditional graphic elements and combine them with the craftsmanship of modern ceramic art and design to realize a reasonable integration. To integrate the traditional graphic elements into modern ceramic art, the emphasis should be laid on innovation. The ceramic art and design cannot be developed without innovation, and cannot fit the context of the times. Traditional graphic elements have a fixed implied meaning, representing the yearning of people towards a better life. In the ceramic art and design, the innovation of traditional graphic elements mainly refers to innovation in patterns of manifestation of the traditional graphic elements based on preservation of their implied meanings to improve the beauty and richness of ceramic.

For example, fish patterns are common in traditional patterns, and most of them appear in the decoration for the New Year because in Chinese the "fish" is homophonic to "redundant", thus the fish pattern means a wish of annually redundant wealth and foods. This kind of patterns are widely applied in the ceramic art due to their implied meanings of auspiciousness. If we want to make innovation in fish patterns, we can add a variety of colors to the drawing of the fish pattern, making the fish pattern more modern and richer in colors, and we can also change the shape or type of the fish, or even draw a mermaid pattern. Another example is the floral pattern; the traditional floral patterns are mostly plum blossom, orchid, bamboo and chrysanthemum, and the types of modern flowers are more diversified. The patterns of flowers with different colors at home and abroad can be artistically processed to draw on the ceramic. The works completed by arranging different flowers through the art of flower arrangement is also wonderful, and drawing such modern works onto the ceramic products will inevitably create more wonderful outcome.

\section{The Development of Fusion of Traditional Graphic Elements in Ceramic Art and Design}

In the eighties of the twentieth century, the design revolution resulted from the computer revolution swept across the world, and China was also influenced and connected with other countries around the world. Many of the western cultures in this period were introduced into China, and there are advantages and disadvantages of the impact of western culture on Chinese culture. In Chinese ceramic art, its integration with the traditional graphic elements is influenced by the western culture and faced some problems; the differences in national culture will lead to deviation in understanding and cause unnecessary misunderstanding. Both ceramic art and traditional graphic elements are the cultural treasures of thousands of years of history in China, which are witness of Chinese history; they are the embodiment of Chinese humanities and arts, and the priceless treasure of the Chinese people as a national heritage and the essence of Chinese culture with far-reaching significance. These are extremely important for the current society where the design talents are scarce. However, at present, courses of the traditional graphics in design major in Chinese colleges and universities are scarce; this is a loss not only to ceramic art and design, but also to most of the design majors. Combined with the current background of the times, infusion of the traditional graphic elements into the ceramic art is a very important attempt. The infusion of traditional graphic elements not only allows students of the major of ceramic art and design to learn the implied meaning, stories or historical background of traditional graphics, as well as the emotion expressed by the graphics, but also stimulates the interest of students to pay attention to humanistic education rather than mechanized or programmed education. The teaching scheme of major of art and design should be improved constantly and innovative; teachers need to learn by themselves to better guide students to better understand the quintessence of ceramic art and design and the traditional graphic elements, thus understanding their connotation deeply. Only in this way can we reasonably integrate the 
traditional graphic elements into ceramic art and design, promoting the development of Chinese ceramic art.

\section{Conclusion}

In summary, the art of ceramic has always been one of the arts with Chinese characteristics. Although it is originated from China, it has significant influence globally during the development of thousands of years of history; the internationalization of ceramic art has been gradually developed and formed. In many western countries, the ceramic art has been researched and explored very deeply; the western art workers value and pay numerous attention to ceramic art. In the history of China for thousands of years, the developments of ceramic art and traditional graphics are the epitome of Chinese human-culture history, which contains Chinese characteristics, and their artistry and cultural connotation are the embodiment of Chinese cultural characteristics. In the course of modern art teaching in colleges and universities, the attempt to integrate these two sections is very meaningful. Once successful, it will be another milestone in the development of humanities and arts in China, having a profound significance for the development of humanities and arts in China.

\section{References}

[1] H.N. Xiang, J. Peng, Z.B. Zou, A study on the mode of "four micro-integrations" in the cultivation of teaching skills of fine arts major under the background of "new normal"- taking Hubei University of Science and Technology as an example, Beauty and Times. 09 (2015) 114116.

[2] R. Li, Research and practice of "interactive teaching mode" in major of art and design- taking the course of creative design as an example, J. Shaoxing Univ. Edu. Edition. 02 (2015) 75-78.

[3] Y. Zhang, Application of practical teaching in teaching of architectural decoration materials and technology, J. Chifeng College. Nat. Sci. Edition. 13 (2012) 233-235.

[4] J. Li, Make the past serve the present, inherite the implication- a brief analysis on the inspiration of chinese traditional graphic elements to modern symbol teaching, Art and Design (Theory). 10 (2011) 175-176.

[5] J. Wang, F. Dong, A brief analysis on the innovative content in the teaching of the basic course of art design in colleges and universities, Mass Literary Magazine, 01 (2013) 230.

[6] S.Q. Bai, A case study on the teaching reform of the basic course of arts and design in colleges and universitie- taking course of "two-dimensional design basis" and "three-dimensional design basis" in central academy of fine arts as an example, Ability and Wisdom. 24 (2016) 181.

[7] R.Q. Zhang, H.Y. Wu, J.H. Xia, X. Jiang, C. Zhang, Discussion on teaching reform of basic courses in major of environmental art design in higher vocational colleges- taking Minxi Vocational and Technical College as an example, Jiannan Literature Classics. 10 (2012) 394$395+397$.

[8] Y.J. Jiang, J.Q. Deng, A brief analysis on the construction and implementation of the projectbased curriculum system for ceramic art design- taking major of ceramic art design in Wuxi Technology Vocational and Technical College as an example, Contemporary Vocational Education. 06 (2011) 7-9.

[9] Y.L. Li, Study on the teaching team construction of the basic course of art design in private colleges- taking Hunan School of Art and Design as an example, Beauty and Times. 02 (2014) 118-120.

[10]J. Chen, H. Wang, Research on the basic course teaching of art major in colleges and universities- taking art design students as an Example, J. Wuxi Vocational Inst. Commerce. 02 (2011) 83-85.

[11]X.C. Sun, Construction of curriculum system of ceramic art design in higher vocational colleges- taking tangshan industrial vocational and technical college as an example, Indus. Technol. Vocational Edu. 01 (2012) 59-62. 